\title{
Leadership in Public Health: Provider Perspectives
}

\author{
Allison F. Wagner ${ }^{1}$, Danilyn Galvez ${ }^{2}$, and Claudio R. Nigg $\oplus^{2}$ \\ ${ }^{1}$ Department of Psychology, University of Hawai 'i at Manoa \\ ${ }^{2}$ Office of Public Health Studies, University of Hawai 'i at Manoa
}

\begin{abstract}
Background and Purpose: The role of public health leaders in shaping decision- and policymaking remains a critical task that encompasses many qualities. The current report attempts to capture the perspectives about this task from those working in the community in Hawai'i. Methods: This is a qualitative descriptive study design. Participants $(n=115 ; 84.3 \%$ female; mean age $=42.3$ [SD $=12.3$ ] years) generated lists of qualities they identified as critical for leadership and developed definitions of a public health leader. Data were coded thematically. Rating differences were subsequently discussed and converged to $100 \%$ interrater reliability in thematic ratings. Results: The most often cited theme in the leadership qualities highlighted a more general skill set, including organizational ability, being reliable, and being consistent $(\mathrm{N}=29,25.44 \%)$. The most cited theme amongst the definitions was the ability to work with others and bring a team together $(\mathrm{N}=37,31.09 \%)$. Of note are several differences from the literature, including having a community orientation, impact, integrity, and being a strategic thinker. Conclusion: The awareness of these perspectives and ability to integrate this information into one's personal leadership style may help shape those individuals hoping to lead the field in the future.
\end{abstract}

(C) 2020 and CC-BY 4.0 licensed by the authors.

Keywords: Leadership, public health, Hawai'i, community

\section{Introduction}

As the political and social climate continues to evolve, the role of public health leaders in shaping decision- and policymaking remains critical (Moodie, 2016). The need to integrate and lead numerous sectors relevant to public health requires an ability utilize a wide lens and non-hierarchical perspective, create a sense of community, comfort with a collaborative and facilitative style, strong ability to communicate, and acknowledgement of and ability to cope with uncertainty (Koh, 2009).

Many different characteristics have been highlighted in the literature as integral to leadership in public health. The qualities cited by this literature vary substantially, from specific skill sets (communication skills, bridge building skills, emotional intelligence), to types of leadership styles (shared leadership, visionary leadership, management style), and consideration of impact (effective change agent, ability to create hope and sense of community) (Alexander, Zakocs, Earp, \& French , 2006; Koh, 2009; Moodie, 2016; and Wright et al., 2000). There is no set definition of characteristics essential for being an effective leader in the public health field.

Multiple authors have written about experts' views on the challenges to leading in public health, as well as the qualities needed to do so (Alexander, Zakocs, Earp, \& French, 2006; Koh, 2009; Moodie, 2016; Wright et al., 2000). This body of knowledge could be enhanced with an understanding of community providers' perspectives on desirable characteristics of a public health leader. The experiences of 
individuals working in various sectors of the community affords them a different perspective on what qualities help to lead the field in a positive direction. Further, discrepancies in opinion that may exist between the experts and individuals in the community may highlight areas for future research to enhance leadership effectiveness. The current brief report attempts to capture these perspectives.

\section{Methods}

\section{Design}

This is a qualitative descriptive study design. The study was approved as exempt by the University of Hawai'i at Mānoa Institutional Review Board.

Data were collected during a series of six trainings (Leadership Skills and Grant Writing for Sustainability) held across all counties of Hawai'i in February and March of 2018 as part of the Strategic Prevention Framework Partnerships for Success (SPF-PFS) grant from the Substance Abuse and Mental Health Services Administration (SAMHSA). A goal of this grant is to increase capacity to prevent substance abuse at the community level. In the specific communities in which these trainings were conducted, a statewide opioid prevention initiative was beginning to take shape, creating a timely opportunity to discuss the ways in which those trained in public health can lead community initiatives. The training agenda included focused didactic and group discussion surrounding leadership skills for sustainability within an organization, including models for leadership, types of leadership, essential leadership skills, and resources for leadership development.

Additionally, the training included information about obtaining funding through grants, types of grants typically available, and the specific components of writing a grant. Participants were recruited by email through networks and workgroups within Hawai' $i$, and participation was voluntary. Participants were provided with Continuing Education (CE) credits for participation in the training, but there were no other incentives. Recruitment of participants was targeted to individuals working in community coalitions and local government divisions, as well as those working in non-profits and private agencies related to public health, and specifically the drug and alcohol abuse field.

\section{Measures}

Open-ended discussions were conducted during each training, with participants generating lists of qualities they identified as critical for leadership as a whole and definitions of a public health leader. These lists were created in group format at the beginning of the training sessions, before information was provided about expert views of leadership in the field.

\section{Analysis}

Data were generated in the form of bullet point lists and single sentence definitions. The data was then transferred to electronic format and using grounded theory was thematically coded by two independent raters. Data regarding qualities of a leader in public health and definitions of a leader in public health were analyzed separately. Initial interrater reliability was $75 \%$. Rating differences were subsequently discussed and converged to $100 \%$ agreement in thematic ratings.

\section{Results}

A total of 115 participants completed the training $(84.3 \%$ female; mean age $=42.3$ years old $(\mathrm{SD}=12.3) ; 71(61.7 \%)$ had $0-5$ years of work experience in their current field).

In total, 114 qualities were generated to describe a good leader. All listed qualities were one to three-word descriptors. Themes identified during thematic analysis, examples of qualities falling under each theme, and the number of qualities per theme are displayed in Table 1. Note that qualities were allowed to represent only one theme. The most often cited theme in these qualities highlighted a more general skill set, including "organized," "reliable," and "consistent" ( $\mathrm{N}=29,25.44 \%)$. 
A total of 119 definitions of a leader in public health were generated. These ranged from single words to full sentences. Using grounded theory, themes were identified. These themes, the number of definitions coded as representing the theme, and percentage of overall definitions including this theme are presented in Table 1. Note that definitions were allowed to be coded as representative of more than one theme, thus the overall count exceeds 119 . This data was coded as such because the nature of the sentences provided for these definitions meant that they often represented a fuller perspective and thus more than one theme, whereas the single word descriptors provided by qualities more typically highlighted one idea. The most cited theme amongst these definitions was the ability to work with others and bring a team together $(\mathrm{N}=37,31.09 \%)$. For example, one definition highlighted effective leadership as "collaborative, participatory, and empowering." Also notable is the extent to which definitions integrated many of the themes into one sentence, thereby highlighting the multifaceted nature of leadership in public health. For example, one definition stated, "Leadership in public health is a dynamic environment where everyone works toward a common goal using different skill sets to promote positive healthy outcomes and prevent disease." This sentence not only highlights a leader's ability to bring others together, but also the ability to be strategic and focus on impact.

Table 1.

Themes Representative of Qualities and Definitions Generated by Participants ( $\mathrm{n}=115)$

\begin{tabular}{|c|c|c|}
\hline $\begin{array}{l}\text { Theme derived from Qualities of a } \\
\text { Good Leader }\end{array}$ & Examples of Qualities of a Good Leader & $\begin{array}{r}\text { \# Qualities } \\
(\%)\end{array}$ \\
\hline General skills & Organized, reliable, responsible, flexible, consistent & $29(25.44)$ \\
\hline Work w/ others/ bring team together & Diplomatic, delegator, approachable, culturally sensitive & $21(18.42)$ \\
\hline Passion, vision, and ability to inspire & Direction, good vision, initiative, inspiring & $17(14.91)$ \\
\hline Communication skills & Good communicator, listener, patience, receptive, respectful & $14(12.28)$ \\
\hline Integrity & Integrity, fair, ethical, honest, trustworthy & $13(11.40)$ \\
\hline Compassion and empathy & Compassionate, emotional intelligence, non-judgmental, & $7(6.14)$ \\
\hline Open-minded & Challenges the process, humble, open-minded & $5(4.39)$ \\
\hline Strategic and problem-solver & Sets goals, strategic, problem solver, innovative & $5(4.39)$ \\
\hline Knowledgeable & Knowledgeable, competent & $3(2.63)$ \\
\hline $\begin{array}{l}\text { Theme derived from Public Health } \\
\text { Leadership Definitions }\end{array}$ & $\begin{array}{l}\text { Examples of Qualities included in Public Health Leadership } \\
\text { Definitions }\end{array}$ & $\begin{array}{r}\text { \# Definitions } \\
(\%)\end{array}$ \\
\hline Work w/ others/ bring team together & Open and collaborative, collaborative $\&$ facilitative style & $37(31.09)$ \\
\hline General skills & Adaptable, accessible, flexible, professional & $22(18.49)$ \\
\hline Strategic and problem-solver & $\begin{array}{l}\text { Recognize and implement change, ability to work with } \\
\text { limited resources and prioritize }\end{array}$ & $19(15.97)$ \\
\hline Community orientation & Helping others, desire to serve, community-driven & $17(14.29)$ \\
\hline Communication skills & $\begin{array}{l}\text { Respect, good communicator, effective communication } \\
\text { skills, tactful }\end{array}$ & $13(10.92)$ \\
\hline Passion, vision, and ability to inspire & Passion, vision, forward thinking, motivate their team & $13(10.92)$ \\
\hline Impact & $\begin{array}{l}\text { Creating results, make a meaningful impact within their } \\
\text { scope, promote positive healthy outcomes }\end{array}$ & $13(10.92)$ \\
\hline Compassion and empathy & Empathetic, understanding, compassion, nonjudgmental & $11(9.24)$ \\
\hline Knowledgeable & Knowledgeable, knowledge of community needs & $10(8.4)$ \\
\hline Integrity & Integrity, trustworthy, holding self to a higher standard & $8(6.73)$ \\
\hline Open-minded & Open, open-minded, humble & $5(4.20)$ \\
\hline Mentor & Someone that coaches, role model & $5(4.20)$ \\
\hline Values & People with the same values, self-care & $3(2.52)$ \\
\hline
\end{tabular}




\section{Discussion}

The current project highlighted several perspectives on the qualities necessary and what it means to be a leader in public health based on community provider experiences. Through adding this perspective to the previous literature, which draws primarily on expert opinion, a wellrounded understanding of leadership in public health emerges. Several of the qualities noted by participants overlap with themes highlighted by previous work, including communication skills, vision, passion, compassion, and ability to build a team (Moodie, 2016; Koh, 2009; Wright et al., 2000). Of note are several differences, including having a community orientation, impact, integrity, and being a strategic thinker. As the field of public health continues to tackle new and evolving issues, those in the field can use this knowledge in their efforts to lead their communities. For example, knowledge of the importance of community orientation could inform the choice to find opportunities to hear community voices, hold additional community meetings, make decisions that are informed by community wishes. A focus on impact could include collaborative discussion of specific outcomes that the community wants to work toward.

The expertise offered by those in the field of public health places them in a uniquely wellsuited position for leadership in public policy. However, we cannot assume that the qualities and knowledge that make a good leader are inherent characteristics. As is true of many skills, specific education and training may be required. Leadership courses should be incorporated in university curriculums. Further, leadership trainings should continue to offer continuing education credits to incentivize leadership skill building for public health professionals. This may, in turn, support the sustainability of organizations and programs. Additionally, these educational courses and workshops should be informed by and responsive to the culture of both the organization and the larger community that an organization serves, as specific qualities associated with "good leadership" may vary based on qualities within the community.

The differences between results of the current analyses and those from previously published work provide some perspective into what community providers in Hawai'i may look for and respond to in a public health leader. The awareness of these perspectives and ability to integrate this information into one's personal leadership style may help those individuals hoping to effectively lead the field in the future. Future research should continue to investigate community providers' perspectives as tools for enhancing the efficacy of current leadership in public health.

\section{Limitations}

Though the current project offers a unique perspective on the qualities key to leadership in public health, there are also several limitations. Generalizability may be limited as the participants are from Hawai'i. Additionally, comprehensive data was not collected on the organizations with which participants worked or specific roles they filled, limiting the ability to analyze by industry. For example, it is unclear whether and how participants may have been involved in leadership roles within their own organizations. Future research should complement the qualitative data with the use of additional quantitative measures to provide a more complete understanding.

\section{References}

Alexander M.P., Zakocs R.C., Earp J.L., French E. (2006) Community Coalition project Directors: What Makes Them Effective Leaders? Journal of Public Health Management Practice, 12(2), 201-209. doi: 10.1097/00124784-200603000-00014

Koh H.K. (2009). Leadership in Public Health. Journal of Cancer Education. 24, S11-S18. doi:10.1080/08858190903400385 
Moodie R. (2016). Learning about self: Leadership skills for public health. Journal of Public Health Research, 5, 679. doi:10.4081/jphr.2016.679

Wright K., Rowitz L., Merkle A., Reid M., Robinson G., Herzog B., ... Baker E. (2000). Competency Development in Public Health Leadership. American Journal of Public Health, 90, 1202-1207. doi: $10.2105 /$ ajph.90.8.1202

Acknowledgements: The authors acknowledge and thank the SPF-PFS team for their continued support and assistance to organize and implement the training. This project was funded by the Strategic Prevention Framework Partnerships for Success Initiative (SPF-PFS) of the Substance Abuse and Mental Health Services Administration (SAMHSA), under grant number: 1U79SP020167-01.

\author{
Author Information \\ Claudio R. Nigg (ORCID ID: 0000-0002-2897-4689) \\ Professor, Institute of Sport Science \\ University of Bern \\ Bremgartenstrasse 145 \\ 3012 Bern, Switzerland \\ Email: claudio.nigg@ispw.unibe.ch
}

